\title{
Farklı ağırlık grubundaki kınalı keklik (Alectoris chukar) yumurtalarında kuluçka öncesi ve sonrası değerler
}

Pre- and post-incubation values of different weight groups of egg laid by chukar partridges (Alectoris chukar)

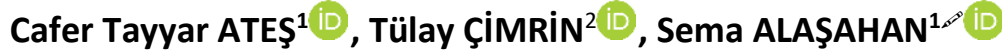 \\ ${ }^{1}$ Hatay Mustafa Kemal University, Veterinary Faculty, Department of Animal Breeding, Antakya-Hatay, Turkey. \\ ${ }^{2}$ Hatay Mustafa Kemal University, Faculty of Agriculture, Department of Animal Science, Antakya-Hatay, Turkey.
}

MAKALE BILGISI / ARTICLE INFO

\section{Makale tarihçesi / Article history: \\ DOI: $10.37908 /$ mkutbd.824067 \\ Geliş tarihi /Received:10.11.2020 \\ Kabul tarihi/Accepted:24.12.2020}

\section{Keywords:}

Egg weight loss, hatchability of fertile eggs, external and internal quality traits.

\footnotetext{
Corresponding author: Sema ALAŞAHAN

$\triangle$ : E mail: alasahan@mku.edu.tr
}

\section{Ö ZET / A B STR A C T}

\begin{abstract}
Aims: This study was aimed at the assessment of pre- and post-incubation values determined for selected characteristics in fertilized and unfertilized eggs of different weight groups laid by chukar partridges.

Methods and Results: Chukar partridge eggs were assigned to two weight groups as follows: Group I: $15.60-20.49 \mathrm{~g}$ and Group II: 20.51-25.63 g. At the end of the incubation period, all eggs in the two weight groups were classified as hatched or unhatched. The hatched eggs were investigated for chick-hatch weight, eggshell weight, and absolute and relative weight loss. The unhatched eggs were investigated for post-incubation egg weight, post-incubation egg content and eggshell weights, absolute and relative weight loss, unfertilized egg and embryonic death numbers and hatchability. The two weight groups of eggs (Group I: 15.60-20.49 g and Group II: $20.51-25.63 \mathrm{~g}$ ) placed in the incubator showed statistically significant differences for egg weight, egg length and width, egg shape index, elongation, eggshell weight and percentage, albumen + egg yolk weight and percentage $(P<0.001)$. It was determined that while the effect of egg weight was negligible on chick-hatch weight $(P>0.05)$, it was significant on absolute and relative incubation egg weight loss in both the hatched and unhatched eggs $(P<0.001)$.

Conclusions: This study demonstrated that the egg weight affected the eggshell, yolk and albumen weights of both fertilized and unfertilized eggs. Furthermore, egg weight was also determined to affect incubation egg weight loss in both fertilized and unfertilized eggs.

Significance and Impact of the Study: In partridges, egg production is seasonal. This seasonality leads to low production numbers for partridge eggs. As male and female partridges are housed together in the same cage, the few number of eggs laid are generally accepted to be fertilized. To ensure flock sustainability, partridge eggs are generally subjected to the incubation process. Thus, in order to achieve the best hatching results, a full understanding of the effects of egg traits on hatching results and hatchling quality is essential. Information on these effects would also increase the success of egg selection for incubation and hatching. In this context, this study aims to contribute to partridge production by determining the effects of egg weight through the investigation of pre- and post-incubation egg characteristics with a view to increase hatching yield.
\end{abstract}

Atıf / Citation: Ateş CT, Çimrin T, Alaşahan S (2021) Pre- and post-incubation values of different weight groups of egg laid by chukar partridges (Alectoris chukar). MKU. Tar. Bil. Derg. 26(1) : 193-199. DOI: 10.37908/mkutbd.824067 


\section{Giriş}

Kınalı kekliği (Alectoris chukar), kum kekliği (Ammoperdix heyi), çil kekliği (Perdix perdix canescens) ve bıldırcın (Coturnix coturnix japonica) gibi yaklaşık 25 adet kanatlı hayvan türü Türkiye Av Kuşları olarak tanımlanmaktadır. Ülkemizde av ve yaban hayatı, T.C. Tarım ve Orman Bakanlığı, Doğa Koruma ve Milli Parklar Genel Müdürlüğü tarafından yönetilmektedir. Av hayvanlarının sahiplendirilmesi ve üretimi resmi çalışma izin belgesine bağlıdır.

Kınalı keklik, yumurta üretimi mevsimsel olan bir kanatlı türüdür. Yumurtalama periyodu 20 Mart-21 Haziran tarihlerini kapsayan ilkbaharda hava sıcaklığının artığı günlerde başlar ve yaz (21 Haziran-21 Eylül) mevsimin sonunda bitmektedir. Ayrıca eşeysel olgunluk yaşı tavuktan daha uzun olup yaklaşık 8-12 aylık yaşa kadar devam eder. Dolayısıyla yumurtlamaya başlama yaşının geç olması ve yumurtlama periyodunun kısa olması kınalı keklik yetiştiriciliğinde elde edilen ürünleri değerli hale getirmektedir (Sarıca ve ark., 2003).

Kınalı keklik yetiştiriciliğinden elde edilen yumurta, et ve gübre üretim miktarları az olan işletme ürünleridir. Kınalı keklik yumurtası genellikle dişi ve erkek kekliğin bir arada yetiştirildiği işletmelerden temin edilen döllü yumurtalardır. Döllü yumurtalar sürü devamlılı̆ı̆ıı sağlamak için civciv üretiminde kullanılmaktadır (Küçükyılmaz, 2003; Kızılaslan ve Şimşek, 2019).

Birçok faktör tarafından etkilenmekte olan yumurta ağırlığı, yumurta kalite özelliklerini ve civciv çıkış ağırlığını dolayısıyla civciv kalitesini ve yaşama gücünü etkileyen önemli bir yumurta özelliğidir (Alkan ve ark., 2007; Alkan ve ark., 2015; Kırıkçı ve ark., 2018; Hegab ve Hanafy, 2019). Civciv çıkış ağırlığının yumurta ağırlığı yüksek olan yumurtalarda fazla olduğu birçok çalışma ile belirlenmiştir. Farklı kanatlı tür yumurtalarında yapılan araştırma sonuçlarında yumurta ağırlığının yumurta kabuk kalınlığı ve embriyo büyüklüğünde farklılığa sebep olabilen etkisiyle kuluçka sonuçlarını değiştirdiği gözlenmiştir (Nestor ve Noble, 1995; Sarı ve ark., 2010; Durmuş, 2014; Yamak ve ark., 2016; Duman ve Şekeroğlu, 2017; Uğurlu ve ark., 2017). Kuluçka döneminde gerçekleşen yumurta ağırlık kaybı, kuluçka sonucunu etkileyen önemli faktörlerden biridir. Yumurta ağırlık kaybı miktarı farklı kabuk kalınlıklarına göre değişik değer göstermektedir. Yumurta ağırlığı kabuk kalınlığını etkileyen önemli bir unsur olup, kuluçkada yumurta ağırlık kaybına dolaylı yönden etkisi olan bir özellik olduğu unutulmamalıdır (Nazlıgül ve ark., 2005; Çağlayan ve ark., 2009; Grzegrzółka ve Gruszczyńska, 2019).

Bu araştırma farklı ağılıktaki döllü ve dölsüz keklik yumurtalarında kuluçka işlemi öncesi ve sonrasında tespit edilen bazı özelliklerin incelenmesi amacıyla yapılmıştır.

\section{MATERYAL ve YÖNTEM}

Araştırma materyali yumurtalar, Malatya Doğa Koruma Milli Parklar 15. Bölge Müdürlüğü Keklik Üretim İstasyonunda yetiştirilen kınalı kekliklerden (Alectoris chukar) temin edilmiştir. Yumurta materyali ortalama 15 aylık yaştaki keklik sürüsünden temin edilmiştir. Kınalı keklik yumurtaları Hatay MKU Deneysel Araştırmalar Uygulama ve Araştırma Merkezi Alternatif Kanatlı Yetiştirme Ünitesinde yürütülmüştür. Çalışmada 263 adet kınalı keklik yumurtası kullanılmıştır. Kuluçkaya yumurtalar yüklenmeden önce bireysel olarak numaralama yapılmıştır. Numara verilen her bir yumurtanın 0.01 grama hassas elektronik terazi yardımıyla yumurta ağırlığı (g), sürgülü kumpas kullanılarak yumurta boyu ve eni $(\mathrm{mm})$ ölçümleri yapılmıştır.

Kınalı keklik yumurtasında yumurta ağırlığı, yumurta boyu ve eni değerleri belirlendikten sonra yumurta ağırlığına göre iki ağırlık grubu oluşturulmuştur. Araştırma grupları; grup I: 15.60-20.49 g ve grup II: 20.51-25.63 g olarak belirlenmiştir. Kınalı keklik yumurtaları toz potasyum permanganat ve sIVI formaldehit kullanılarak dezenfekte edilmiştir. Dezenfekte işleminden sonra yumurta tablaları kuluçka makinasına yerleştirilmiştir. Kuluçka işlemi gelişim ve çıkış dönemleri bir arada kombine kuluçka makinası içinde olacak şekilde sıcaklık 37.5 oC ve nispi nem \%65 olarak uygulanmıştır. Kuluçka süresi sonunda her bir gruptaki yumurtalar civciv çıkışı olan ve olmayan yumurtalar olarak tanımlanmıştır. Deneme gruplarında belirlenen özellikler ve hesaplama bilgileri aşağıda sunulmuştur.

\section{Denemede kullanılan toplam yumurta özellikleri}

Kuluçka makinasına yüklenen toplam yumurtalardan tartım ile belirlenen başlangıç yumurta ağırlığı kullanılarak aşağıdaki özellikler belirlenmiştir (Paganelli ve ark., 1974);

Kabuk ağılığı $(\mathrm{g})=0.0482 \times$ (başlangıç yumurta ağırlı̆̆ı)1.132

$A k+$ sarı ağırlığı $(g)=$ (başlangıç yumurta ağırlığı $-k a b u k$ ağırlığı)

Kabuk oranı $(\%)=$ (Kabuk ağırlığı / başlangıç yumurta ağırlığı) $\times 100$

$A k+$ sarı oranı $(\%)=(A k+$ satı ağırlığı $/$ başlangıç yumurta ağırlığı) $\times 100$

Uzama (Elongasyon) $=($ Yumurta boyu $/$ yumurta eni) 
Şekil İndeksi (\%) = (Yumurta eni / yumurta boyu) $\times 100$ Civciv Çıkışı Olan Yumurta Özellikleri

Kuluçka süresi olan 24 gün itibariyle yumurtadan çıkan civcivler tartılarak civciv çıkış ağırlığı ve civciv çıkışı olan yumurtaların kabuk ağırlıkları tartılarak kayıt edilmiștir. Başlangıç yumurta ağılıkları, civciv ağırlığı ve civciv çıkışı olan yumurta kabuk ağırlığı değerleri kullanılarak aşağıdaki özellikler belirlenmiştir;

Civciv dönüşüm oranı (\%)= (Civciv çıkış ağırlığı / Başlangıç yumurta ağırlı̆̆ı) $\times 100$

Kabuk oranı $(\%)=($ Civciv çıkışı olan yumurta kabuk ağırlığı / Başlangıç yumurta ağırlığı) x 100

Kuluçka süresince mutlak ağırlık kaybı $(g)=$ (Başlangıç yumurta ağırlığı - (Civciv ağırlığı + Kabuk ağırlığı))

Kuluçka süresince bağıl ağılık kaybı $(\%)=$ (Kuluçka süresince mutlak ağırlık kaybı (g) / Başlangıç yumurta ağırlığı) x 100

Civciv Çıkışı Olmayan Yumurta Özellikleri

Kuluçka koşullarında makine iç ortamında 27 gün $(24+3$ gün) sonunda civciv çıkışı olmayan yumurtalar tartılarak kuluçka sonu yumurta ağırlıkları belirlenmiştir. Daha sonra yumurtalar ekvatoral bölgeden kırılarak içerikleri boşaltılmıştır. Yumurta kabuk ağırlığı ve içerik ağırlığı tartılarak belirlenmiştir. Ayrıca çıkış gücünü hesaplamak için embriyonik ölüm olan yumurta sayıları belirlenmiştir. Başlangıç yumurta ağırlığı ve kuluçka sonrası yumurta ağırlığına ait değerler kullanılarak aşağıdaki özellikler hesaplanmıştır;

Kuluçka sonrası yumurta içerik oranı= (Kuluçka sonrası yumurta içerik ağırlığı / Kuluçka sonrası yumurta ağırlı̆̆ı) $x 100$

Kuluçka sonrası yumurta kabuk oranı= (Kuluçka sonrası yumurta kabuk ağırlığı / Kuluçka sonrası yumurta ağırlığı) $x 100$

Kuluçka süresince mutlak ağırlık kaybı $(g)=$ (Başlangıç yumurta ağırlığı - Kuluçka sonrası yumurta ağırlığı) Kuluçka süresince bağıl ağılık kaybı $(\%)=$ (Kuluçka süresince mutlak ağırlık kaybı / Başlangıç yumurta ağırlığı) $\times 100$

\section{İstatistik analizler}

Çalışmada yumurta ağırlık gruplarından elde edilen veriler IBM SPSS 22 paket programı kullanılarak deneme grup ortalamalarının birbirinden farklı olup olmadığını iki Örnek T Testi (bağımsız iki grubun karşılaştırılması) analizi ile saptanmıştır. Araştırmada grupların çıkış gücü Ki-kare testi ile analiz yapılmıştır.

\section{BULGULAR ve TARTIŞMA}

Kuluçka makinasına yüklenen yumurta ağırlık gruplarının incelenen özellikler bakımından aralarındaki farklılık önemli $(P<0.001)$ olarak saptanmıştır (Tablo 1). Yumurta ağırlı̆̆ının yüksek olduğu grup II'de tartım ve ölçümle bulunan özellikler grup I'deki yumurta değerlerinden yüksek olarak tespit edilmiştir. Araştırmada kuluçka makinasına yüklenen toplam kınalı keklik yumurta ağırlığı ortalama $20.91 \mathrm{~g}$ olarak saptanmıştır. Benzer şekilde kınalı keklik yumurta ağırlığını Kırıkçı ve ark. (2018) $<19-23<$ g arasında ve Özkan (2020) 17.59-22.24 g arasında, kaya keklik yumurta ağırlığını ise Çetin ve ark. (2008) 21.77- 22.26 g ve Çağlayan ve ark. (2009) 20.62 g olarak bildirmişleridir.

Çizelge 1. Toplam kuluçkalık yumurta özellik değerleri

Table 1. Trait values in total hatching eggs

\begin{tabular}{lllll}
\hline Özellikler & $\begin{array}{l}\text { Grup I } \\
(15.60-20.49 \mathrm{~g})\end{array}$ & $\begin{array}{l}\text { Grup II } \\
(20.51-25.63 \mathrm{~g})\end{array}$ & Genel & $\mathbf{P}$ \\
\hline Yumurta ağırlığı (g) & $19.20 \pm 0.11$ & $21.99 \pm 0.09$ & $20.91 \pm 0.11$ & 0.000 \\
\hline Yumurta boyu (mm) & $39.96 \pm 0.16$ & $42.22 \pm 0.11$ & $41.34 \pm 0.11$ & 0.000 \\
\hline Yumurta eni (mm) & $29.08 \pm 0.06$ & $30.19 \pm 0.05$ & $29.76 \pm 0.05$ & 0.000 \\
\hline Şekil indeksi (\%) & $72.86 \pm 0.30$ & $71.57 \pm 0.19$ & $72.07 \pm 0.17$ & 0.000 \\
\hline Uzama & $1.375 \pm 0.01$ & $1.399 \pm 0.00$ & $1.390 \pm 0.00$ & 0.000 \\
\hline Kabuk ağırlığı (g) & $1.37 \pm 0.01$ & $1.59 \pm 0.01$ & $1.51 \pm 0.01$ & 0.000 \\
\hline Ak + sarı ağırlı̆ı (g) & $17.83 \pm 0.10$ & $20.40 \pm 0.08$ & $19.40 \pm 0.10$ & 0.000 \\
\hline Kabuk oranı (\%) & $7.12 \pm 0.01$ & $7.25 \pm 0.00$ & $7.20 \pm 0.01$ & 0.000 \\
\hline Ak + sarı oranı (\%) & $92.88 \pm 0.01$ & $92.75 \pm 0.00$ & $92.80 \pm 0.01$ & 0.000 \\
\hline
\end{tabular}

Çalışmada yumurta dış kalite özellik değerlerine, ak+sarı ağırlığına ve oranına yumurta ağırlığının etkisinin bulunduğu, bu özelliklerin grup II'deki yumurtalarda grup I'deki yumurtalardan daha yüksek $(P<0.001)$ olduğu saptanmıştır (Tablo 1). Kabuk, kabuk altı zarlar, ak ve sarının birleşmesi sonucu oluşan yumurtanın yapısındaki 
bu unsurların ağırlık değerlerinin pozitif olarak bütün yumurta ağırlığı ile değiştiği birçok çalışma sonucunda rastlanan bir gerçek olmasından dolayı grup II'deki yumurtalar için yüksek olması normal olarak kabul edilmiştir. Alkan ve ark. (2015)'ları kınalı keklik yumurtalarını ağırlıklarına göre 4 gruba ayırdıkları çalışmada yumurta ağırlığının yumurta boyu ve eni, şekil indeksi, yumurta kabuk ağırlığı ve oranı, ak ağırlığı ve oranı, sarı ağırlığı ve oranı değerlerine etkili olduğunu bildirilmiştir.

Civciv çıkışı olan yumurtalara ve civcivlere ait bazı özellik değerleri Tablo 2'de sunulmuştur. Yumurta ağırlığının civciv çıkış ağırlığına etkisi önemsiz $(P>0.05)$ iken civciv dönüşüm oranına etkisi önemli $(P<0.001)$ olduğu saptanmıştır. Yumurta ağırlığının kuluçka süresince mutlak ve bağıl ağırlık kaybına etkisinin olduğu tespit edilmiştir $(P<0.001)$. Kuluçka işlemi sonucunda civciv çıkışı olan yumurtaların özellikleri ve civciv dönüşüm oranı bakımından yumurta ağılığının olumlu etkisi tespit edilmiş, ancak civciv çıkış ağırlığına rakamsal etkinin olmasına rağmen istatistiksel etkisinin olmadığı saptanmıştır (Tablo 2). Civciv çıkış ağırlığının yumurta ağırlığından etkilendiğini gösteren birçok çalışma (Çağlayan ve ark., 2009; Yamak ve ark., 2016; Ewonetu ve Kasaye, 2018; Hegab ve Hanafy. 2019) olmasına rağmen bu çalışma sonucunda rakamsal olarak grup II'deki yumurtalardan çıkan civcivler ağır olmuştur. Çalışmada yumurta ağırlığı düşük olan grup I'de civcive dönüşüm oranı grup II'den yüksek olmuş, ancak bu sonuç farklı kanatlı yumurtalarında yapılan yumurta ağırığının civcive dönüşüm oranına etkisinin olduğu sonucundan farklılık gösterdiği saptanmıştır (Duman ve Şerekoğlu, 2017; Iqbal ve ark., 2017). Civciv dönüşüm oranının ağırlık kaybı düşük olduğu grupta (grup I) yüksek çıkması, kuluçka süresince oluşan yumurta ağırlık kaybının doğal bir sonucudur.

Çizelge 2. Civciv çıkışı olan yumurtaların ve civcivlerin özellikleri

Table 2. Traits in the hatched eggs and chicks

\begin{tabular}{llll}
\hline Özellikler & $\begin{array}{l}\text { Grup I } \\
(15.60-20.49 \mathrm{~g})\end{array}$ & $\begin{array}{l}\text { Grup II } \\
(20.51-25.63 \mathrm{~g})\end{array}$ & $\mathbf{P}$ \\
\hline Civciv çıkış ağırlı̆̆ (g) & $16.18 \pm 0.22$ & $15.90 \pm 0.24$ & 0.407 \\
\hline Dönüşüm oranı (\%) & $83.61 \pm 0.83$ & $72.56 \pm 1.35$ & 0.000 \\
\hline Başlangıç yumurta ağırlığı (g) & $19.22 \pm 0.17$ & $22.00 \pm 0.18$ & 0.000 \\
\hline Yumurta boyu (mm) & $40.05 \pm 0.26$ & $42.55 \pm 0.19$ & 0.000 \\
\hline Yumurta eni (mm) & $29.15 \pm 0.10$ & $30.19 \pm 0.11$ & 0.000 \\
\hline Şekil indeksi (\%) & $72.89 \pm 0.50$ & $71.00 \pm 0.37$ & 0.003 \\
\hline Uzama & $1.374 \pm 0.01$ & $1.410 \pm 0.01$ & 0.004 \\
\hline Kabuk ağırlı̆ı (g) & $1.97 \pm 0.06$ & $1.82 \pm 0.04$ & 0.030 \\
\hline Kabuk oranı (\%) & $10.29 \pm 0.33$ & $8.27 \pm 0.18$ & 0.000 \\
\hline Kuluçka süresince mutlak ağırlık kaybı (g) & $1.20 \pm 0.15$ & $4.25 \pm 0.34$ & 0.000 \\
\hline Kuluçka süresince bağıl ağırlık kaybı (\%) & $6.19 \pm 0.76$ & $19.10 \pm 1.39$ & 0.000 \\
\hline
\end{tabular}

Kuluçka işlemi esnasında kuluçka ortam koşulları ve embriyo gelişimine bağlı olarak yumurta ağırlığında kayıp meydana gelir. Bu ağırlık kaybı genel olarak yumurtaların gelişim makinasından çıkım makinasına aktarım esnasında yumurta transfer ağırlığı belirlenerek mutlak ve bağıl ağırlık kaybı olarak ifade edilmektedir. Çalışmada kuluçka süresince mutlak ve bağıl ağırlık kaybı bulunmuş olup grup II'deki yumurtalarda grup I'deki yumurtalardan daha fazla ağırlık kaybı olduğu saptanmıştır (Tablo 2 ve Tablo 3). Kuluçka başlangııından transfere kadar geçen sürede yumurtadaki ağırlık kaybının dış ve iç ortam arasındaki gaz değişimi, embriyonun metabolizma ve gelişimi ile ilgili olduğunu gösteren birçok çalışma yapılmıştır (Christensen, 1983; Soliman ve ark., 1994; Çağlayan ve ark., 2010; Yamak ve ark., 2016). Dolayısıyla kabuk kalınlığı yani gözenek uzunluğu gaz değişimini etkileyerek ağırlık kaybının kabuk kalınlığına göre farklılık göstermesine sebep olmaktadır. Araştırmanın yumurta ağırlığı düşük olan grup I'de yumurta ağırlık kaybının düşük olması çalışma sonuçlarıyla benzerlik göstermektedir. Ancak Hegab ve Hanafy (2019) tarafından bıldırcın yumurtalarını ağırlıklarına göre küçük ve büyük olarak tanımladıkları ve her iki grup için kabuk kalınlığının 0.20 mm olduğunu ifade ettikleri çalışmada küçük gruptaki yumurtalarda 
Çizelge 3. Kuluçka sonrası civciv çıkışı olmayan yumurta özellikleri

Table 3. Trait of unhatched eggs in post-Incubation

\begin{tabular}{lccc}
\multicolumn{1}{c}{ Özellikler } & Grup I & Grup II & P \\
& $(15.60-20.49 \mathrm{~g})$ & $(20.51-25.63 \mathrm{~g})$ & $22.03 \pm 0.10$ \\
\hline Başlangıç Yumurta Ağırlığı (g) & $19.11 \pm 0.14$ & 0.000 \\
\hline Kuluçka sonrası Yumurta Ağırlığı (g) & $17.22 \pm 0.19$ & $19.01 \pm 0.16$ & 0.000 \\
\hline Kuluçka sonrası Yumurta içerik ağırlığı (g) & $14.56 \pm 0.18$ & $16.03 \pm 0.15$ & 0.000 \\
\hline Kuluçka sonrası kabuk ağırlığı (g) & $2.67 \pm 0.06$ & $2.99 \pm 0.06$ & 0.001 \\
\hline Kuluçka sonrası İçerik oranı (\%) & $84.46 \pm 0.33$ & $84.27 \pm 0.30$ & 0.696 \\
\hline Kuluçka sonrası kabuk ağırlık oranı (\%) & $15.55 \pm 0.33$ & $15.73 \pm 0.30$ & 0.696 \\
\hline 0-27 gün Mutlak ağırlık kaybı (g) & $1.90 \pm 0.81$ & $3.01 \pm 0.16$ & 0.000 \\
\hline 0-27 gün Bağıl ağırlık kaybı (\%) & $9.87 \pm 0.81$ & $13.58 \pm 0.69$ & 0.001 \\
\hline
\end{tabular}

kuluçka sırasındaki bağıl ağırlık kaybının daha yüksek olduğu ifade edilmiştir.

Araştırmada yumurta ağırlığının kuluçka sonuçlarından olan çıkış gücü üzerine etkisinin olduğu $(P<0.05)$ belirlenmiş olup çıkış gücü grup I'deki yumurtalarda grup II'deki yumurtalardan daha yüksek tespit edilmiştir (Tablo 4). Çalışmada kuluçka sonuçlarını değerlendirme özelliklerinden olan çıkış gücü oranı en iyi grup ı'deki yumurtalarda belirlenmiş ve yumurta ağırlığının bu özelliğe olumlu etkisinin olduğu saptanmıştır (Tablo 4). Çizelge 4. Grupların çıkış gücü değerleri

Çizelge 4. Grupların çıkış gücü değerleri

Table 4. Hatchability of fertile eggs of trial groups

\begin{tabular}{lll}
\hline Grup & Çıkış gücü (\%) & Ki kare \\
\hline Grup I(15.60-20.49 g) & 87.8 & 0.029 \\
\hline Grup II (20.51-25.63 g) & 69.6 & 4.452
\end{tabular}

\section{SONUÇ ve ÖNERILER}

Bu araştırmada kınalı keklik yumurta ağırlığının döllü ve dölsüz yumurtaların dış ve iç yapı unsurları üzerine etkisinin olduğu saptanmıştır. Ayrıca kuluçka süresi boyunca döllü ve dölsüz yumurtalarda gerçekleşen ağırlık kaybına yumurta ağırlığının etkisinin önemli düzeyde olduğu tespit edilmiştir. Bu sonuçlar, yumurta ağırlığı baz alınarak diğer yumurta özelliklerinin tahmininde kullanılması mümkündür. Ayrıca yumurta ağırlığı bakımından birörnek yumurtaların kuluçka makinasına yüklenmesi ile birörnek civciv çıkış ağırlığı ve sağlıklı bakım besleme dönemi açısından olumlu sonuç vermesi işletme karlıı̆ğı açısından pozitif bir yaklaşımdır.

\section{ÖZET}

Amaç: Bu çalışmada farklı yumurta ağırlık gruplarındaki döllü ve dölsüz kınalı keklik yumurtalarının kuluçka işlemi öncesi ve sonrasında özelliklerin belirlenmesi amaçlanmıştır.
Benzer şekilde Kırıkçı ve ark. (2018) tarafından kınalı keklik yumurtalarını ağırlık olarak 6 gruba ayırdıkları çalışmada en düşük çıkış gücünü en ağır yumurta grubunda bildirmiş olup bu özellik için yumurta ağırlığının çalışma sonucundan farklı olarak rakamsal olduğunu ifade etmişlerdir. Aynı şekilde Çağlayan ve ark. (2009) kaya keklik yumurtalarında yaptıkları çalışmada çıkış gücünü en hafif yumurta grubunda en düşük olarak ve yumurta ağırlı̆ının etkisinin rakamsal düzeyde olduğunu bildirmiştir.
Yöntemler ve Bulgular: Kınalı keklik yumurtaları yumurta ağırlıklarına göre grup I: $15.60-20.49 \mathrm{~g}$ ve grup II: 20.51-25.63 g ve olarak sınıflandırılmıştır. Yumurtalar, kuluçka makinasına yüklenmeden bireysel olarak yumurta ağırlı̆̆ı, yumurta boyu ve eni belirlenmiştir. Kuluçka işlemi sonrası her bir gruptaki yumurtalar civciv çıkışı olan ve olmayan olarak tanımlanmıştır. Civciv çıkışı olan yumurtalarda; civciv çıkış ağırlı̆̆ı, kabuk ağırlığı, mutlak ve bağıl ağılık kaybı belirlenmiştir. Civciv çıkışı olmayan yumurtalarda; kuluçka sonu yumurta ağırlığı, kuluçka sonu yumurta içerik ve kabuk ağırlığı, mutlak ve bağıl ağılık kaybı, döllülük ve embriyonik ölüm gerçekleşen yumurta sayısı belirlenerek çıkış gücü belirlenmiştir. Kuluçka makinasına yüklenen yumurta ağırlık gruplarında (grup I: 15.60-20.49 g ve grup II: 20.51-25.63 g) yumurta ağırlığı, yumurta boyu ve eni, şekil indeksi, uzama değeri, kabuk ağırlığı ve oranı, ak+sarı ağılığı ve oranı bakımından farklılık önemli $(P<0.001)$ olarak saptanmıştır. Yumurta ağırlığının civciv çıkış ağırlığına etkisi önemsiz ( $P>0.05)$, civciv çıkışı olan 
ve olmayan yumurtalarda kuluçka süresince mutlak ve bağıl ağırlık kaybına etkisinin önemli olduğu tespit edilmiştir $(P<0.001)$.

Genel Yorum: Araştırmada döllü ve dölsüz yumurtaların kabuk, sarı ve ak ağırlıkları üzerine yumurta ağırlığının etkili olduğu saptanmıştır. Ayrıca yumurta ağırlığının döllü ve dölsüz yumurtalarda kuluçka süresi boyunca gerçekleşen ağırık kaybına etkilemiştir.

Çalışmanın Önemi ve Etkisi: Yumurta üretimi kekliklerde mevsimseldir. Yumurta veriminin belli dönemlerde olması yumurta sayısının az olmasına neden oluşturur. Yetiştirme yapısı gereğince dişi ve erkek kekliklerin aynı kafeste tutulması, az sayıda üretilen keklik yumurtasının döllü olduğu kabulüne nedendir. Genelde yumurtalar sürü devamlılığı için kuluçka işlemine tabi tutulmaktadır. Dolayısıyla en yüksek kuluçka sonucunun elde edilmesi için yumurta özelliklerinin kuluçka sonuçlarına ve çıkan civciv kalitesine etkisinin bilinmesi yumurta seçiminde önem arz etmektedir. Bu anlamda çalışmada yumurta ağırlı̆ının kuluçka öncesi ve sonrası özelliklerini belirleyerek kuluçka verimliliğini artırmak için keklik yetiştiriciliğine katkı yapan bir çalışmadır.

Anahtar kelimeler: Yumurta ağırlık kaybı, çıkış gücü, yumurta dış ve iç kalite özellikleri.

\section{Çıkar Çatışması Beyanı}

Makale yazarları aralarında herhangi bir çıkar çatışması olmadığını beyan ederler.

\section{Araştırmacıların Katkı Oranı Beyan Özeti}

Yazarlar makaleye eşit oranda katkı sağlamış olduklarını beyan ederler.

\section{KAYNAKLAR}

Alkan S, Karabag K, Balcioglu MS, Galic A (2007) Determination of some egg traits and body weights in chukar partridge (Alectoris chukar). Akdeniz Univ. J. Fac. Agric. 20: 225-228.

Alkan S, Galiç A, Karslı T, Karabağ K (2015) Effects of egg weight on egg quality traits in partridge (Alectoris chukar). Journal of Applied Animal Research 43(4): 450-456.

Christensen VL (1983) Distribution of pores on hatching and nonhatching turkey eggs. Poultry Science 62: 1312-1316.

Çağlayan T, Garip M, Kırıkçı K, Günlü A (2009) Effect of egg weight on chick weight, egg weight loss and hatchability in rock partridges ( $A$. graeca). Ital. J. Anim. Sci. 8: 567-574.
Çağlayan T, Alaşahan S, Çetin O, Kırıkçı K, Günlü A (2010) Effects of egg weight and length of storage period on chick weight and hatchability performance of pheasants (Phasianus colchicus). J. Food Agric. Environ. 8: 407-410.

Çetin O, Kırıkçı K, Garip M, Günlü A, Çağlayan T (2008) Kekliklerde ( $A$. graeca) yumurtalama zamanının kuluçka sonuçları ile bazı yumurta özelliklerine etkisi. Atatürk Üniversitesi Vet. Bil. Derg. 3(1): 11-17.

Durmuş i (2014) Yumurta kalite özelliklerinin kuluçka sonuçlarına etkisi. Akademik Ziraat Dergisi 3(2): 9599.

Duman MI, Şekeroğlu A (2017) Effect of egg weights on hatching results, broiler performance and some stress parameters. Brazilian Journal of Poultry Science 19(2): 255-262.

Ewonetu KS, Kasaye A (2018) Effect of egg weight on post-hatch performance of white leghorn chicken breed from day-old to laying age. Journal of Poultry Research 15(2): 16-22.

Grzegrzółka B, Gruszczyńska J (2019) Correlations between egg weight, early embryonic development, and some hatching characteristics of Japanese quail (Coturnix japonica). Turkish Journal of Veterinary and Animal Sciences 43: 253-258.

Hegab IM, Hanafy AM (2019) Effect of egg weight on external and internal qualities, physiological and hatching success of japanese quail eggs (Coturnix coturnix japonica). Brazilian Journal of Poultry Science 21(3): 001-008.

Iqbal J, Mukhtar N, Rehman ZU, Khan SH, Ahmad T, Anjum MS, Pasha RH, Uma S (2017) Effects of egg weight on the egg quality, chickquality, and broiler performance at the later stagesof production (week 60 ) in broiler breeders. J. Appl. Poult. Res. 26: 183191.

Kırıkçı K, Çam M, Başer E, Akbulut NK, Bilgiç MA (2018) Kınalı Kekliklerde Yumurta Ağırlığının Kuluçka Sonuçları Üzerine Etkisi. Bahri Dağdaş Hayvancılık Araştırma Dergisi 7(1): 1-6.

Kızılaslan A, Şimşek ÜG (2019) Kınalı Kekliklerde (Alectoris chukar) Bazı Yumurta ve Kuluçka Özelliklerinin Araştırılması. F. Ü. Sağ. Bil. Vet. Derg. 33(1): 19-23.

Küçükyılmaz K (2003) Kekliklerde yumurta verimi ve kuluçka. Lalahan Hay. Araşt. Enst. Derg. 43(2): 41-49.

Nazlıgül N, Türkyılmaz MK, Bardakçıŏlu HE (2005) Effects of hatching egg weight on hatching chick weight, posthatching growth performance and liveability in japanese quails (Coturnix coturnix japonica). İstanbul Univ. Vet. Fak. Derg. 31(2): 33-40. 
Nestor KE, Noble DO (1995) Influence of selection for Increased egg production, body weight and shank width of turkeys on egg composition and relationship of the egg traits to hatchability. Poultry Science 74 : 427-433.

Özkan ÇÖ (2020) Damızlık Kınalı Kekliklerde (Alectoris chukar) Meselen E Liquid Takviyesinin Yumurta Verimi Üzerine Etkisinin Belirlenmesi. ADYÜTAYAM, 8(1): 31-37.

Paganelli CV, Olszzowka A, Ar A (1974) The avian egg: Surface area, volume and density. Condor 76: 319325.

Sarı M, Tilki M, Saatcı M, Işık S, Önk K (2010) Japon bıldırcınlarında (Coturnix coturnix japonica) ebeveyn yaşı, yumurta ağırı̆̆ı̆ ve şekil indeksinin kuluçka özellikleri ve yaşama gücü üzerine etkisi. F. Ü. Sağ. Bil. Vet. Derg. 24(2): 93-97.

Sarıca M, Camcı Ö, Selçuk E (2003) Bılıdırcın, Sülün, Keklik, Etçi Güvercin, Beç Tavuğu ve Devekuşu Yetiştiriciliği. Ondokuz Mayıs Üniversitesi, Ziraat Fakültesi, Ders Kitabı No: 4, Samsun. 1-42.
Soliman FNK, Rizk RE, Brake J (1994) Relationship between shell porosity, shell thickness, egg weight loss and embryonic development in japanese quail eggs. Poultry Science 73: 1607-1611.

Uğurlu M, Daş YK, Akdağ F, Atmaca E, Salman M, Teke B, Arslan S (2017) Effect of egg weight and amount of protoporphyrin and biliverdin in the egg shell on hatching characteristics and embryonal mortality in pheasants (Phasianus colchicus). Ankara Üniv. Vet. Fak. Derg. 64: 117-124.

Yamak US, Sarica M, Boz MA, Ucar A (2016) The effect of eggshell thickness on hatching traits of partridges. Brazilian Journal of Poultry Science Special Issue: 013018. 